\title{
Avaliação Estocástica de Risco de Colapso: O Caso do Abastecimento de Água de Campina Grande-PB-Brasil
}

\author{
Francisco Jácome Sarmento \\ Universidade Federal da Paraíba, CT, CEP 58059-900, Campus I, João Pessoa, PB, (083)-226-1945
}

Recebido: 17/12/03 - revisado: 28/04/04 - aceito: 19/06/04

\section{RESUMO}

No presente artigo, o risco de colapso no abastecimento de água a partir de um reservatório é modelado em um espaço pentadimensional, no qual o eixo do tempo é construído utilizando-se um modelo estocástico de geração de vazões para rios intermitentes na sintese de diversas realizações possiveis do processo estocástico representativo da vazão afluente. O agravamento do risco de colapso ao longo de um ano futuro é ajustado através de regressão não-linear múltipla. O procedimento proposto é empregado para o caso do reservatório de abastecimento de água de Campina Grande/PB - Açude Epitácio Pessoa (Boqueirão), para o qual é também avaliado o risco de colapso total.

Palavras-Chave - modelo estocástico, risco de colapso, simulação de operação.

\section{PREVISIBILIDADE VERSUS PROBABILIDADE}

A tomada de decisão no campo do gerenciamento dos recursos hídricos certamente seria bastante simplificada caso fosse possível prever as futuras vazões afluentes aos mananciais. Em se tratando de variáveis hidrológicas com influência sobre o comportamento de reservatórios formados por barragens, a compreensão, na profundidade suficiente, da estrutura de distribuição temporal de ocorrência de anos úmidos e secos representa, sem dúvida, uma parcela substancial na definição de modelos voltados à inferência sobre trajetórias futuras do reservatório.

É plausível a idéia de que anos secos tendam a suceder anos secos e que anos úmidos sucedam anos úmidos (persistência) e que, por outro lado, mudanças de estado (seco/úmido ou úmido/seco) podem ocorrer de modo arbitrariamente rápido, quebrando a continuidade da seqüência de anos secos ou úmidos (descontinuidade).

Nesse contexto, prever o futuro seria, portanto, "equacionar" a disputa de forças entre persistência e descontinuidade, disponibilizando o meio de se determinar qual delas prevalece em um dado intervalo de tempo futuro. Em termo práticos, é óbvio que sequer conhecemos todas as variáveis envolvidas.

O caminho alternativo consiste em utilizar um modelo probabilístico que permita gerar tantas possíveis realizações quantas sejam necessárias da variável "vazão afluente" no ano vindouro.

As séries sintéticas, estatisticamente idênticas à histórica, embora não representem informação nova, são, em si, a explicitação de informações subjacentes na série histórica, relevantes para a emulação do conjunto de possíveis futuros comportamentos do armazenamento no reservatório em foco.

Considerando as efeitos da persistência e da descontinuidade, pode ser tentada uma leitura probabilística da dinâmica geradora da série disponível, presumindo-se que a disposição temporal das preponderâncias de um e de outro segue uma certa distribuição de freqüências que, como uma balança, ora pende para a persistência ora para a descontinuidade.

Uma alternativa de certa recorrência na literatura consiste na utilização de cadeias de Markov na representação de processos em que as ocorrências futuras mostram dependência do passado em diferentes graus de "memória”. As probabilidades de transição (mudanças de estado), base das cadeias de Markov, representadas na forma de matriz, são estimadas de uma amostra de $n$ anos passados, sendo tanto melhor a estimativa quanto maior for $\mathrm{o}$ valor de $n$.

Fundamental na estimativa da matriz de transição vem a ser a definição do limite para se classificar um determinado ano como seco ou úmido. Como a estimativa das probabilidades de transição depende diretamente do número de anos secos e úmidos e de sua disposição seqüencial no tempo, definir o limite entre seco e úmido altera o valor da estimativa. Caso seja adotada a média como sendo um parâmetro de referência (acima dela o ano é úmido, caso contrário será seco), convém lembrar que a influência antrópica pode catalizar determinados processos naturais (desertificação, por exemplo), com influência direta sobre o rendimento da bacia, fazendo com que a 
Tabela 1 - Número de ocorrências de Transições / probabilidade de ocorrência.

\begin{tabular}{cccccc}
\hline \hline Período* & $\begin{array}{c}\text { Persistência } \\
\text { Seco - Seco }\end{array}$ & $\begin{array}{c}\text { Descontinuidade } \\
\text { Úmido - Seco }\end{array}$ & $\begin{array}{c}\text { Descontinuidade } \\
\text { Seco - Úmido }\end{array}$ & $\begin{array}{c}\text { Persistência } \\
\text { Úmido-Úmido }\end{array}$ & $\begin{array}{c}\text { \% de anos se- } \\
\text { cos } / \text { úmidos }\end{array}$ \\
\hline $1928-1991$ & $29 / 0,67$ & $14 / 0,67$ & $14 / 0,33$ & $7 / 0,33$ & $67 / 33$ \\
$1938-1991$ & $23 / 0,64$ & $13 / 0,72$ & $13 / 0,36$ & $5 / 0,28$ & $67 / 33$ \\
$1917-1980$ & $29 / 0,66$ & $15 / 0,75$ & $15 / 0,34$ & $5 / 0,25$ & $69 / 31$ \\
$1917-1970$ & $23 / 0,64$ & $13 / 0,72$ & $13 / 0,36$ & $5 / 0,28$ & $67 / 33$ \\
\hline \hline
\end{tabular}

* O limite para considerar um ano seco ou úmido foi igual à média da subsérie.

Tabela 2 - Número de ocorrências de Transições / probabilidade de ocorrência para dois limites de seca

\begin{tabular}{cccccc}
\hline \hline Período & $\begin{array}{c}\text { Persistência } \\
\text { Seco - Seco }\end{array}$ & $\begin{array}{c}\text { Descontinuidade } \\
\text { Úmido - Seco }\end{array}$ & $\begin{array}{c}\text { Descontinuidade } \\
\text { Seco - Úmido }\end{array}$ & $\begin{array}{c}\text { Persistência } \\
\text { Úmido-Úmido }\end{array}$ & $\begin{array}{c}\text { \% de anos se- } \\
\text { cos } / \text { úmidos }\end{array}$ \\
\hline $1917-1953^{*}$ & $17 / 0,68$ & $8 / 0,68$ & $7 / 0,28$ & $5 / 0,42$ & $68 / 32$ \\
$1917-1953^{* *}$ & $23 / 0,77$ & $7 / 0,90$ & $6 / 0,23$ & $1 / 0,14$ & $81 / 19$ \\
$1954-1991^{*}$ & $18 / 0,69$ & $8 / 0,80$ & $8 / 0,31$ & $2 / 0,20$ & $72 / 28$ \\
$1954-1991^{* *}$ & $10 / 0,50$ & $10 / 0,625$ & $10 / 0,50$ & $6 / 0,375$ & $56 / 44$ \\
\hline \hline
\end{tabular}

*O limite para considerar um ano seco ou úmido foi igual à média da subsérie.

** $\mathrm{O}$ limite para considerar um ano seco ou úmido foi igual à média de longo termo.

média do escoamento seja alterada, acrescentando-se ao processo uma tendência muitas vezes identificável apenas em séries muito longas (raramente disponíveis).

\section{Representação dos efeitos da persistência e da descontinuidade}

Os efeitos da persistência e da descontinuidade, contrapostos ao longo do tempo, originam a disposição de seqüências secas e úmidas que compõem uma série de vazões anuais. Admitindo-se que o encadeamento de anos secos e úmidos ao longo do tempo pode ser representado por uma cadeia de Markov de ordem 1, podemos então escrever a matriz M como sendo:

\section{$\operatorname{Seco}(S) \quad \operatorname{Umido}(U)$}

$\operatorname{Seco}(S) \quad P(i=S \mid(i-1)=S) \quad P(i=S \mid(i-1)=U)$

Úmido $(U) \quad P(i=U \mid(i-1)=S) \quad P(i=U \mid(i-1)=U)$

$i=$ ano atual

$(i-1)=$ ano anterior

onde $P(i=S \mid(i-1)=S)$ significa a probabilidade do ano atual $i$ ser seco, dado que o anterior foi seco, ou seja, $m_{1,1}$ significa a probabilidade da persistência de uma seca se impor. O termo $m_{2,1}$ igual a $P(i=U \mid(i-1)=S)$ significa a probabilidade da descontinuidade se impor à persistência. Os dois outros componentes da matriz estão relacionados à persistência e à descontinuidade de anos úmidos, possuindo, portanto, significados análogos aos descritos.

A matriz M pode ser estimada diretamente da série histórica, iniciando-se com a definição de um limite a partir do qual o ano será considerado seco (limite de seca). Yevjevich (1967) define seca como sendo uma seqüência de valores medidos, inferiores ao limite de seca. A seqüência deve ser, no mínimo, precedida e sucedida de pelo menos um valor superior ao valor limite adotado. Implicações da definição desse limite na análise de secas são analisadas por Dracup (1980) e Chang (1990).

\section{Sensibilidade da matriz de transição}

Como exemplo, tomemos uma série de vazões pseudo-históricas (obtida através de modelo chuva-vazão), no reservatório de Boqueirão (PB) com 75 anos de extensão e média anual de $59,5 \mathrm{~m}^{3} \mathrm{~s}^{-1}$. A primeira metade da série (1917-1953) é relativamente mais seca do que a segunda metade (1954-1991), com médias anuais de 45,03 $\mathrm{m}^{3} \mathrm{~s}^{-1} \mathrm{e}$ $72,17 \mathrm{~m}^{3} \mathrm{~s}^{-1}$, respectivamente. A Tabela 1 resume os valores encontrados de ocorrências de persistências e descontinuidades para diversas subséries da série pseudo-histórica.

A sensibilidade dos parâmetros da Matriz de Transição está mais relacionada com o limite de seca do que com a inclusão ou exclusão de décadas úmidas ou secas. Porém, devemos também alertar para o fato de que, no caso em foco, a retirada, no máximo, das duas primeiras décadas e das duas últimas, não chega a descaracterizar a subsérie em relação à série completa, ou seja, mesmo com a retirada daquelas décadas permanecem outras também marcadamente secas e úmidas.

Dividindo-se uma dada série histórica relativamente extensa em trechos, espera-se que essas subséries (trechos da série total disponível) preservem a estrutura de dependência probabilística (representada na matriz $M$ ) independentemente da mesma haver sido, em média, mais 
Tabela 3 - Matriz de Transição para diversos limites de seca (percentual da média)

\begin{tabular}{cccccc}
\hline \hline $\begin{array}{c}\text { Limite de Seca } \\
(\boldsymbol{\%} \overline{\boldsymbol{Q}})\end{array}$ & $\begin{array}{c}\text { Persistência } \\
\text { Seco - Seco }\end{array}$ & $\begin{array}{c}\text { Descontinuidade } \\
\text { Úmido - Seco }\end{array}$ & $\begin{array}{c}\text { Descontinuidade } \\
\text { Seco - Úmido }\end{array}$ & $\begin{array}{c}\text { Persistência } \\
\text { Úmido-Úmido }\end{array}$ & $\begin{array}{c}\% \text { de anos se- } \\
\text { cos } / \text { úmidos }\end{array}$ \\
\hline 100 & $34 / 0,67$ & $17 / 0,70$ & $16 / 0,33$ & $7 / 0,30$ & $69 / 31$ \\
80 & $29 / 0,62$ & $18 / 0,66$ & $17 / 0,36$ & $10 / 0,37$ & $63 / 27$ \\
50 & $23 / 0,57$ & $17 / 0,50$ & $16 / 0,41$ & $18 / 0,52$ & $54 / 46$ \\
30 & $13 / 0,45$ & $16 / 0,35$ & $16 / 0,55$ & $29 / 0,64$ & $39 / 61$ \\
20 & $7 / 0,32$ & $15 / 0,28$ & $15 / 0,68$ & $37 / 0,71$ & $30 / 70$ \\
10 & $4 / 0,40$ & $6 / 0,09$ & $6 / 0,60$ & $58 / 0,91$ & $13 / 87$ \\
0 & $0 / 0,00$ & $0 / 0,00$ & $0 / 0,00$ & $74 / 1,00$ & $0 / 100$ \\
\hline \hline
\end{tabular}

úmida ou mais seca. A Tabela 2 mostra que ao dividirmos a série de afluências a Boqueirão em duas metades, em função da média utilizada como limite de seca, têm-se algumas alterações na matriz de transição.

Os números fornecidos na Tabela 2 mostram que ao considerarmos a média dos 75 anos da série pseudohistórica como limite de seca, comparativamente com a adoção da média anual da primeira metade, obviamente estaremos aumentando o número de anos considerados secos e, no caso da segunda metade, diminuindo este número. Como a primeira metade da série possui média inferior ao valor da média histórica da série completa, ao fazermos uso da matriz de transição obtida com base na média desta metade seria como se adotássemos um percentual da média da série completa como limite de seca. No caso da segunda metade, ocorre que esta média é superior à da séria completa, seria portanto como se multiplicássemos à média da série completa por um valor maior do que 1.

Se pensarmos na população de matrizes de transição como sendo um conjunto obtido a partir da variação do parâmetro que determina o valor de seus elementos (probabilidades de transição), ou seja, variando-se o limite de seca, verifica-se que:

- à medida que aumentamos o limite para o ano ser considerado seco, a probabilidade de transição úmido para úmido diminui (o número de anos úmidos diminui), enquanto que a probabilidade de úmido para seco aumenta. Na Tabela 2, observa-se que com a adoção do limite de seca como sendo a média histórica de longo termo, os eventos secos tornam-se mais persistentes (probabilidade de transição seco para seco aumenta) e a descontinuidade em um evento seco ser seguido de um evento úmido também cai. Portanto, todas as variações apontam para uma persistência de eventos secos na primeira metade da série;
- à medida que diminuímos o limite para o ano ser considerado seco, a probabilidade o número de anos úmidos aumenta, refletindo-se na queda da probabilidade de transição de anos úmido para secos e aumento na probabilidade transição de úmido para úmido. Conforme se pode observar na Tabela 2, os eventos úmidos se tornam mais persistentes ao adotarmos a média de longo termo como limite de seca, enquanto que as mudanças de estado de anos úmidos para secos diminuem e as transições de seco para úmido aumentam. A ênfase aqui vem a ser nos eventos úmidos, o que reflete bem o fato de a segunda metade haver sido relativamente mais úmida do que a primeira.

A necessidade de dispormos da série mais longa possível, que englobe ampla parcela da variabilidade da vazão, é aqui enfatizada com os resultados obtidos, separando-se a série em duas metades. A explicitação de que se trata de uma metade seca (a primeira) e outra úmida (a segunda) só ocorre ao utilizarmos a média de longo termo como limite de seca.

A sensibilidade da matriz de transição à variação do limite de seca pode ainda ser observada com base na Tabela 3 (reservatório Boqueirão), construída tomando-se o limite de seca como sendo uma percentagem da média de longo termo.

A Tabela 3 mostra claramente que a persistência seca cresce com o incremento do limite de seca, enquanto que a persistência de eventos úmidos acentua-se com a diminuição deste limite. Adotar um limite dentro de um certo intervalo de variação na geração de séries de vazão significa "dosar" a própria persistência de secas e cheias nas séries sintetizadas. A faixa de variação dessa "dosagem" poderia ser aquela que levasse da persistência máxima de anos secos à persistência máxima de anos úmidos. A fronteira do domínio no qual isso é válido pode ser estabelecida observando-se a preservação dos parâmetros estatís- 
ticos (média, desvio padrão, coeficiente de variação, etc) das séries geradas.

\section{Procedimento de geração de séries sintéticas anuais}

O esquema de geração proposto pode ser resumido nos seguintes passos:

\section{1 - estabelecer um limite de seca;}

2 - estimar, a partir da série disponível, a matriz $\mathrm{M}$ de probabilidades;

3 - o primeiro ano da série pode ser gerado a partir do último ano da série histórica, iniciando-se então o encadeamento de anos secos e úmidos segundo a matriz $\mathrm{M}$ estimada, tendo-se ainda como hipótese que a persistência e a descontinuidade podem ser representadas em cada ano i, por $u_{i}$, números aleatórios uniformemente distribuídos entre 0 e 1 . A definição do estado a ser assumido no ano a ser gerado é feita da seguinte forma:

$$
\begin{aligned}
& \text { - Se o ano anterior é seco: } \\
& u_{i} \geq m_{2,1} \Rightarrow q s_{i}=\sec o \\
& u_{i}<m_{2,1} \Rightarrow q s_{i}=\text { úmido } \\
& \text { - } \mathrm{Se} \mathrm{O} \text { ano anterior é úmido: } \\
& u_{i} \geq m_{2,2} \Rightarrow q s_{i}=\sec o \\
& u_{i}<m_{2,2} \Rightarrow q s_{i}=\text { úmido }
\end{aligned}
$$

Observe-se na primeira relação acima, que se $u_{i}$ supera a probabilidade da descontinuidade imperar, a seca se prolongará por mais 1 ano. Caso contrário, a descontinuidade prevalece quebrando a seqüência seca. $\mathrm{Na}$ relação $u_{i} \geq m_{2,2} \Rightarrow q s_{i}=\sec o$, temos que se $u_{i}$ supera a probabilidade de persistência de anos úmidos, a seqüência é quebrada e a descontinuidade se impõe, resultando em ano seco. Caso contrário, a persistência de mais um ano úmido é admitida;

4 - definido o estado (seco ou úmido) do ano a ser gerado, resta determinar o valor da vazão. Teremos dois caminhos a serem seguidos, em função do estado seco ou úmido (Sarmento, 1997):

- se o estado é seco, o valor é retirado de uma distribuição uniforme de números aleatórios variando entre zero e o valor do limite de seca considerado na definição da Matriz M;

- se o estado é úmido, o valor da vazão sintética é obtido através de um esquema auto-regressivo de ordem 1, com distribuição de probabilidade gama de três parâmetros. O conjunto de números aleatórios gama é gerado a partir de uma distribuição de Poisson e uma distribuição expo- nencial, conforme proposto por Obeysekera e Yevjevich (1985)

A série histórica é apenas um retrato do passado, uma imagem de como atuaram a persistência e a descontinuidade. Ao sintetizarmos séries temporais a partir de um procedimento que tem seus parâmetros obtidos da série histórica não estamos gerando informação nova, mas sim extraindo dos dados disponíveis determinadas características (aqui resumidas na matriz M), que nos permitem obter diferentes movimentos da balança: possíveis formas de oscilação futura.

O modelo descrito é um aperfeiçoamento do modelo proposto e validado por Sarmento (1999), baseado em um procedimento utilizado por Molinas (1990) na geração estocástica de vazão para o semi-árido do Ceará. As séries sintéticas anuais podem ser desagregadas em séries mensais. O procedimento sugerido para tanto é o chamado Método dos Fragmentos proposto por Svanidze (1964). A adequação do procedimento na preservação dos parâmetros estatísticos mensais foi previamente verificada e encontra-se descrita em em Sarmento e Ferreira Filho (1988).

\section{Análise de risco de colapso de um reservatório submetido a uma retirada fixa}

A determinação da ocorrência do colapso total de um reservatório submetido a uma determinada retirada fixa, entendido como a exaustão do volume útil, depende da previsão dos aportes hídricos naturais futuros, permitindo então a aplicação de modelos de simulação apropriados.

No caso dos rios intermitentes do semi-árido nordestino, a previsão de vazões mensais afluentes com precisão suficiente apresenta, em função do semestre ao qual pertence o mês a ser projetado, um grau de dificuldade extremamente pequeno - caso do semestre hidrológico seco, onde as vazões afluentes são nulas - e um outro extremamente elevado, caso do semestre úmido.

Se por um lado a característica de intermitência de outra parte torna a previsão de vazões para alguns meses óbvia, por outro contribui para aumentar a complexidade da previsão para os meses secos, pois a interposição de valores nulos na série destrói a correlação serial entre os últimos meses do semestre seco e os primeiros do semestre úmido - exatamente aquele no qual ocorrem os aportes hídricos significativos.

A abordagem do problema sob um senso probabilístico permite constatar que cada tomada de decisão sobre retirada de água nos meses que antecedem o período úmido em um reservatório com baixo armazenamento (probabilidade de esvaziamento diferente de zero antes da ocorrência do próximo inverno) possui um risco correspondente. Assim para cada tomada de decisão de retirada 
de água haverá uma probabilidade de colapso estimada sobre diversas possíveis realizações do processo estocástico gerador das vazões mensais futuras.

A pergunta agora é: como será este futuro? $\mathrm{Na}$ abordagem probabilística aqui adotada, a resposta a esta pergunta é construída a partir do passado, ou seja, com base nas informações contidas na série histórica o futuro será "construído".

\section{“Construindo" o futuro}

As oscilações de preponderância de persistência e de descontinuidade na série histórica disponível podem ser representadas, conforme já apresentado, por uma matriz de probabilidades M. Dada a marcante variabilidade de vazões, típica de regiões semi-áridas, o futuro poderá realizarse dentro de um intervalo que vai de um ano extremamente seco a um ano extremamente úmido. A pergunta agora passa a ser: podemos admitir uma simetria para o futuro, ou seja, o próximo ano realizar-se como um ano seco possui a mesma probabilidade de realizar-se como um ano úmido? Mais uma vez olhando o passado, podemos, com base na série histórica, computar a probabilidade de ocorrência de 1 ano seco (úmido), 2 anos secos (úmidos) subseqüentes, etc.

Tomando-se o eixo do tempo como sendo um eixo horizontal ao longo do qual desenvolve-se o processo estocástico em foco, denominaremos $M_{m}^{H}$ uma matriz formada por dois vetores-coluna representativos da probabilidade de $m$ anos secos (coluna 1)/úmidos (coluna 2) serem seguidos por mais 1 ano seco/úmido:

$M_{m}^{H}=\left(\begin{array}{ll}p_{1,1}^{m} & p_{1,2}^{m} \\ p_{2,1}^{m} & p_{2,2}^{m}\end{array}\right)$ com

$M_{m}^{H}=\left(\begin{array}{cc}p_{1,1}^{m} & 0 \\ p_{2,1}^{m} & 0\end{array}\right) \Leftrightarrow q_{n}^{h}=\sec o$

$M_{m}^{H}=\left(\begin{array}{cc}0 & p_{1,2}^{m} \\ 0 & p_{2,2}^{m}\end{array}\right) \Leftrightarrow q_{n}^{h}=$ úmido

onde $q_{n}^{h}$ é a vazão anual no último ano da série histórica.

Seja $M_{m}^{V}$ a matriz de transição estimada a partir das $k$ realizações possíveis do processo estocástico para o ano futuro. Para que a estrutura probabilística contida no passado possa ser preservada, as $k$ realizações do processo estocástico irão "construir" o futuro a partir da igualdade:

$M_{m}^{V}=M_{m}^{H}$

Caso tenhamos na matriz acima $p_{1,1}^{m}=p_{2,1}^{m}$, estaremos na situação em que a "probabilidade da persistência" prevalecer seria igual a "probabilidade da descontinui- dade" prevalecer, apontando assim, sob essa ótica, para um futuro simétrico.

Assim, se por exemplo $q_{n}^{h}=" \sec o^{\prime}$, a amostra de $k$ realizações futuras da variável vazão anual deverá ser, portanto, composta de $n^{\prime}$ séries iniciando com o estado "seco" e $n$ " séries iniciando com o estado "úmido" com:

$n^{\prime}=p_{1,1}^{m} \times k$

$n^{\prime \prime}=p_{2,1}^{m} \times k$

A utilização do modelo proposto representa uma forma de se estimar, segundo metodologia justificada, valores numéricos para variáveis que, face à impossibilidade da previsão, ficariam apenas no campo da incerteza subjetiva. Uma das vantagens dessa mensuração probabilística consiste na possibilidade de comparar situações passadas e presentes, permitindo uma avaliação de ações no campo da gestão da água.

\section{Estimativa da probabilidade de colapso}

A análise será procedida sobre um período de tempo que se estende do semestre seco de um dado ano ao semestre seco do ano seguinte. A simulação com valores de vazões afluentes sintéticas dar-se-á, portanto, para um número máximo de 12 meses.

Consideremos um reservatório com volumes de armazenamento máximo e mínimo iguais a $V_{\max }$ e $V_{\min }$, respectivamente. Se o reservatório armazena um determinado volume $V_{i, j}$ no ano i e mês j, a simulação de operação para os meses futuros, considerando $q_{r}$ a vazão retirada, irá ocorrer segundo a seguinte regra:

$q_{r}=\left\{\begin{array}{l}Q \Leftrightarrow V_{j+1} \geq V_{\text {min }} \\ 0 \Leftrightarrow\left[V_{j}+Y_{j}-E_{j}\left(\frac{A_{1}+A_{2}}{2}\right)\right]<V_{\text {min }} \\ Q_{v}=\left[V_{j}+Y_{j}-E_{j}\left(\frac{A_{1}+A_{2}}{2}\right)\right]-V_{\text {min }} \Leftrightarrow V_{j+1}<V_{\text {min }}\end{array}\right.$

$V_{i+1} \leq V_{\max }$

$i=1,2, \ldots, n$

$j=1,2,3, \ldots, 12$

onde

$V$ : volume de água armazenada $\left(\mathrm{m}^{3}\right)$

$Q_{v}$ : vazão de falha $\left(\mathrm{m}^{3} \mathrm{~s}^{-1}\right)$

$Q$ : valor de vazão assumido por $q_{r}\left(\mathrm{~m}^{3} \mathrm{~s}^{-1}\right)$ em função das condições de armazenamento 
$E_{j}$ : evaporação no mês $j(\mathrm{~m})$

$A_{1}$ e $A_{2}$ : áreas do espelho d'água do reservatório no início e no fim de mês $\left(\mathrm{m}^{2}\right)$

A realização da simulação a partir do armazenamento em um dado mês inicial, para a amostra de $k$ realizações possíveis para o ano hidrológico seguinte, resultará em $k$ diferentes armazenamentos para os meses futuros considerados. Em outras palavras, há $k$ diferentes possíveis trajetórias para o reservatório no horizonte futuro. Dependendo do mês inicial, do armazenamento inicial e da vazão retirada, existe um determinado número de trajetórias que levarão a um volume de referência, que se for igual ao volume mínimo, caracterizará o colapso total. Caso o volume de referência seja o armazenamento no mês para o qual foi iniciada a simulação, valores de armazenamento inferiores no mesmo mês, no ano seguinte, significam que a política de retiradas praticada transfere o problema para o próximo ano, só que de maneira relativamente mais grave. Essa probabilidade será denominada $r^{p}$. A probabilidade $r^{c}$ de ocorrência do colapso total em um dado mês $j$ futuro é estimado por:

$r_{j}^{c}=\frac{n_{j}^{c}}{k}$

onde:

$r_{j}^{c}=$ probabilidade de colapso no mês $j$ futuro

$n_{j}^{c}=$ número de trajetórias que levam ao colapso no mês $j$ futuro

\section{Estudo de Caso: Abastecimento de água de Campina Grande - PB}

A cidade de Campina Grande está localizada no planalto da Borborema, no estado da Paraíba. Com uma população de cerca de 340.000 habitantes, dotada de distrito industrial, corresponde à segunda maior cidade do estado. Seu suprimento hídrico tem como fonte o reservatório Epitácio Pessoa (Boqueirão), com capacidade de $450 \mathrm{mi}$ lhões de $\mathrm{m}^{3}$, que vem atravessando, há vários anos, graves problemas no atendimento das demandas, não sendo rara a adoção de rigorosos racionamentos até mesmo para atendimento ao abastecimento humano. O período chuvoso na bacia (rio Paraíba) ocorre, em geral, nos trimestres fevereiro-março-abril ou março-abril-maio.

Em decorrência da indisponibilidade de séries históricas extensas para o reservatório estudado, foi calculada uma série pseudo-histórica de vazões através do mo- delo chuva-vazão MODHAC (Lanna e Schwarzbach, 1988), com intervalo diário de simulação. A série obtida se estende de 1917 a 1991, perfazendo assim 75 anos de informações. Os estudos que levaram ao seu estabelecimento são parte do Projeto de Transposição do Rio São Francisco - Inserção Regional (SEPRE/FUNCATE, 1999) e podem ser resumidos nas seguintes etapas:

- coleta de todos os postos fluviométricos disponíveis para a bacia do rio Paraíba, bem como bacias adjacentes;

- análise de consistência das séries fluviométricas disponíveis da perspectiva das curvas-chave, continuidade de vazões e rendimentos;

- definição das séries de melhor qualidade;

- calibração de modelo chuva-vazão (MODHAC) às séries consideradas de qualidade;

- análise final, identificando o posto fluviométrico de maior adequação tanto da perspectiva quantitativa (ajustamentos) como da perspectiva qualitativa (comparação com bacias melhor monitoradas);

- quando possível, validação do modelo calibrado para um trecho de série não utilizado no procedimento de calibração;

- geração da série pseudo-histórica de deflúvios para o reservatório.

O posto fluviométrico utilizado na calibração do modelo foi Poço de Pedras, com dados disponíveis no período de 1970 a 1991. A Tabela 4 resume os principais indicadores característicos da bacia.

Tabela 4 - Índices característicos da bacia

\begin{tabular}{|c|c|c|c|}
\hline $\begin{array}{c}\text { Área } \\
\mathrm{km}^{2}\end{array}$ & $\begin{array}{c}\text { Precipitação } \\
\text { média }(\mathrm{mm})\end{array}$ & $\begin{array}{c}\text { Deflúvio médio } \\
\text { anual }(\mathrm{mm})\end{array}$ & $\begin{array}{c}\text { Rendimento } \\
\text { da bacia }(\%)\end{array}$ \\
\hline 7.904 & 389,0 & 18,9 & 4,9 \\
\hline
\end{tabular}

O padrão de evaporação adotado para a simulação do reservatório é o mesmo adotado pela Companhia de Água e Esgoto da Paraíba (CAGEPA). Embora esses valores sejam superiores àqueles assumidos nos estudos da SEPRE/FUNCATE, resolveu-se por sua adoção para se preservar o caráter oficial da informação no nível estadual. A Tabela 5 apresenta esses valores.

\section{Resultados obtidos}

O futuro provável foi "construído" com um total de 500 séries sintéticas com extensão de 75 anos e mesmos parâmetros estatísticos da série histórica mensal e anual (média, desvio padrão, coeficientes de variação, assimetria, 
Tabela 5 - Padrão de evaporação (E) utilizado na simulação do reservatório

\begin{tabular}{|c|c|c|c|c|c|c|c|c|c|c|c|c|}
\hline MÊS & JAN & FEV & MAR & ABR & MAI & JUN & JUL & AGO & SET & OUT & NOV & DEZ \\
\hline $\mathrm{E}(\mathrm{mm})$ & 178 & 144 & 181 & 152 & 165 & 121 & 101 & 132 & 154 & 163 & 197 & 211 \\
\hline
\end{tabular}

Tabela 6 - Risco de agravamento da situação de colapso

\begin{tabular}{|c|c|c|}
\hline $\begin{array}{l}\text { MÊS } \\
\text { BASE }\end{array}$ & EQUAÇÃO AJUSTADA* & $r^{* *}$ \\
\hline Jul. & $r^{p}=0,123351 \times\left(V_{\text {julho }}+q_{r} \times p_{1,1}^{m}\right)^{1,088526}$ & 0,98 \\
\hline Ago. & $r^{p}=0,298191 \times\left(V_{\text {agosto }}+q_{r} \times p_{1,1}^{m}\right)^{0,952557}$ & 0,96 \\
\hline Set. & $r^{p}=0,325577 \times\left(V_{\text {setembro }}+q_{r} \times p_{1,1}^{m}\right)^{0,945774}$ & 0,97 \\
\hline Out. & $r^{p}=0,337065 \times\left(V_{\text {outubro }}+q_{r} \times p_{1,1}^{m}\right)^{0,946649}$ & 0,97 \\
\hline Nov. & $r^{p}=0,322364 \times\left(V_{\text {novembro }}+q_{r} \times p_{1,1}^{m}\right)^{0,958340}$ & 0,98 \\
\hline Dez. & $r^{p}=0,29050 \mathbb{z}\left(V_{\text {dezembro }}+q_{r} \times p_{1,1}^{m}\right)^{0,98052}$ & 0,98 \\
\hline \multicolumn{3}{|c|}{$\begin{array}{l}* 10 \% V_{\max } \leq V_{j} \leq 35 \% V_{\max }, 0 \leq q_{r} \leq 3 m^{3} / s \\
\text { olumes em } \% \text { de } V_{\max }, q_{r} \mathrm{em} \mathrm{m}^{3} / \mathrm{s} \text { e } 0<p_{1,1}^{m}<100\end{array}$} \\
\hline
\end{tabular}

e correlação serial e autocorrelação ambas de ordem 1). Foram consideradas 5 variações para o futuro, correspondendo a 5 diferentes proporções de séries iniciando com anos secos e úmidos: $15 \%$ secos e $85 \%$ úmidos, $25 \%$ secos e $75 \%$ úmidos, $50 \%$ secos e $50 \%$ úmidos, $75 \%$ secos e $25 \%$ úmidos e, finalmente, $90 \%$ iniciando com ano seco e $10 \%$ iniciando com ano úmido. A parametrização permitiu o ajustamento da probabilidade $r^{p}$ de agravamento da situação de colapso no ano seguinte como função do armazenamento presente, da vazão retirada e da probabilidade de o ano seguinte ser um ano seco. As equações propostas, com parâmetros obtidas por regressão não-linear múltipla, são apresentadas na Tabela 6 .

O risco de agravamento da situação de armazenamento em relação aos mesmos meses, em anos consecutivos, apresenta um comportamento notoriamente diferenciado para o mês de julho em relação aos demais. $\mathrm{Na}$ bacia do médio Paraíba, o mês de julho corresponde ao fim da temporada de afluências significativas ao reservatório.

Fixando-se a retirada e o armazenamento, e ao aproximarmo-nos de dezembro, o risco de agravamento da situação de colapso aumenta. Isso ocorre em decorrência das perdas por evaporação serem maiores para os espelhos d'água no primeiro semestre do ano (janeiro a junho). Partindo-se do mês de julho, as taxas de evaporação incidem sobre o reservatório deplecionado, ao qual afluirão volumes significativos somente no primeiro semestre do ano seguinte. Decorre também deste fato o comportamento praticamente idêntico do risco para os meses de novembro e dezembro, ou seja, pouco influi no risco o fato do armazenamento ser relativo a novembro ou dezembro: para esses meses, a influência maior vem a ser preponderantemente da vazão retirada.

Tabela 7 - Valores de $r^{p}$ para a situação estudada

\begin{tabular}{|l|c|c|}
\hline Avaliação via: & Julho/2004 & Outubro/2004 \\
\hline Análise de Risco & 16,0 & 19,0 \\
\hline Equação Ajustada & 16,6 & 22,9 \\
\hline
\end{tabular}

O modelo pode também ser utilizado para avaliar o quão acertada foi a decisão de postergação de racionamento em tempo presente. Para isso, basta considerar, para um dado mês $j$, o risco de colapso para a demanda com e 
Tabela 8 - Alguns resultados obtidos para situações simuladas

\begin{tabular}{ccccccc}
\hline \hline $\begin{array}{c}\text { Ano do } \\
\text { Evento }\end{array}$ & $\begin{array}{c}r_{j u l}^{p} \\
(\%)\end{array}$ & $\begin{array}{c}V_{j u l} \\
(\%)\end{array}$ & $\begin{array}{c}q_{r} \\
\left(\mathrm{~m}^{3} / \mathrm{s}\right)\end{array}$ & $\begin{array}{c}p_{1,1}^{m} \\
(\%)\end{array}$ & Condição & $\begin{array}{c}\Delta V \\
\left(10^{6} \mathrm{xm}^{3}\right)\end{array}$ \\
\hline 1919 & 29,4 & 35,0 & 2,5 & 47,0 & $S \mid S$ & $-101,7$ \\
1921 & 14,7 & 33,5 & 2,0 & 23,6 & $\operatorname{SSS} \mid S$ & $+25,2$ \\
1924 & 5,1 & 20,3 & 1,8 & 5,8 & $\operatorname{SSSSSS} \mid S$ & $+320,6$ \\
1929 & 17,6 & 35,0 & 2,0 & 30,1 & $\operatorname{SS} \mid S$ & $-26,0$ \\
1954 & 6,4 & 26,0 & 2,0 & 5,8 & $\operatorname{SSSSSS} \mid S$ & $-62,0$ \\
1951 & 16,5 & 31,0 & 2,5 & 23,6 & $\operatorname{SSS} \mid S$ & $-77,8$ \\
\hline \hline
\end{tabular}

sem racionamento: se o racionamento for postergado em 1 mês, o volume armazenado no mês $j+1$ será menor do que aquele na hipótese de racionamento. Com base nos dois volumes (o volume com a implementação do racionamento e o volume atual com o racionamento postergado), faz-se então a análise e tem-se, assim, em quanto o risco de colapso foi incrementado com a postergação. Da mesma forma, podemos realizar a avaliação com relação ao agravamento da situação de colapso. Neste último caso, se tomarmos os meses de julho e o mês atual de outubro (2003), teremos:

$$
\begin{gathered}
V_{\text {julho }}=138.252 .163 m^{3} \cong 31 \% V_{\max } \\
V_{\text {outubro }}=123.470 .500 m^{3} \cong 27 \% V_{\max }
\end{gathered}
$$

Embora a retirada média total do ano passado tenha sido da ordem de $q_{r}=2,80 \mathrm{~m}^{3} / \mathrm{s}$, consideraremos a retirada média ao longo do ano corrente (2003), que é de $q_{r}=1,80 \mathrm{~m}^{3} / \mathrm{s}$. Sabendo-se que vivenciamos o terceiro ano consecutivo com escoamento abaixo da média (2001, 2002 e 2003), obtemos, com base na série pseudo-histórica, $p_{1,1}^{m}=p(S \mid S S S)=32,6 \%$. A Tabela 7 resume os resultados encontrados utilizando-se o procedimento descrito, bem como as equações ajustadas. Os números mostram que a situação de julho para outubro tornou-se relativamente mais grave.

Embora possa parecer conservador, ao lidar com colapso absoluto, ou seja, evento extremo de suspensão total do abastecimento d'água, torna-se desejável se trabalhar com retiradas pequenas o suficiente para anular o valor de $p_{j}^{c}$ para todo $j$. No caso específico analisado, o porte da cidade abastecida praticamente descarta a hipótese de uso de frotas de carros-pipa, tornando imperiosa a parcimônia na adoção da estratégia de retiradas de vazão nas situações de crise.

A consistência dos resultados apresentados pelo modelo para situações com futuro conhecido foi averiguada para vários eventos da série pseudo-histórica, tendo-se julho como mês base. Trata-se de situações de crise gera- das propositadamente, no mês de julho, em anos anteriores a anos registrados na série pseudo-histórica como úmidos e secos. Conforme se observa na Tabela 8, tomando-se como exemplo o evento de 1919, temos:

1- reservatório armazenava em julho de 1918, 35\% da sua capacidade máxima;

2- a vazão retirada de julho de 1918 a julho de 1919 foi de $2,5 \mathrm{~m}^{3} \mathrm{~s}^{-1}$;

3- ano de 1918 foi antecedido por um ano úmido (1917); portanto, a probabilidade condicional seria de apenas 1 ano (1918) ser sucedido por outro seco, o que na série pseudo-histórica ocorre 35 vezes, resultando assim em $p_{1,1}^{1}=47 \%$;

4- a probabilidade de agravamento da situação em julho de 1919 foi $r^{p}=29,4 \%$;

5- em julho de 1919, o reservatório apresentou uma redução de volume, em relação a julho de 1918, da ordem de 101,7 milhões de $\mathrm{m}^{3}$.

Das situações mostradas na Tabela 8, duas são de particular interesse: os eventos de 1924 e de 1954. Principalmente pelo fato de a probabilidade de que um sétimo ano seco suceda 6 anos secos ser relativamente baixa, obtêm-se valores para $r_{j u l h o}^{p}$ relativamente baixos $(5,1 \% \mathrm{e}$ 6,4\%, respectivamente). Porém, o ano de 1954 se impôs como mais um ano seco, ocasionando, para a retirada considerada, uma redução de cerca de 62 milhões de $\mathrm{m}^{3}$ em relação a julho de 1953.

Uma das vantagens do modelo proposto consiste no fato de ser necessário apenas o conhecimento do estado (seco/úmido) do ano considerado presente para a geração das séries sintéticas, pois como já descrito anteriormente, a persistência só é considerada em termos do estado e não do valor da variável. Assim, em uma seqüência de dois anos úmidos, o segundo ano poderá apresentar uma vazão superior ou não ao primeiro: o que interessa é que seja maior do que a média de longo termo. Isso nos permite aplicar o modelo para anos para os quais sabe-se apenas ter sido seco ou úmido, sem se dispor da vazão anual afluente. 


\section{REFERÊNCIAS}

CHANG, T. J.,1990: Effects of Drought on Streamflow Characteristics. In: Journal of Irrigation and Drainage Engeneering Vol. 116 N. 3 , p. 332-341.

DRACUP, J. A.; LEE K.S.; PAULSON, E. G. Jr.,1980: On the definition of droughts. In: Water Resources Research 16 (2) , p. 297-302.

LANNA, A.E.; SCHWARZBACH, M., 1988: MODHAC Modelo Hidrológico Auto-Calibrável. Instituto de Pesquisas Hidráulicas da UFRGS.

MOLINAS, P. A., 1990: Procedimento Markoviano para Geração de Séries Sintéticas no Semi-Arido, PERH-CE, Plano Estadual de Recursos Hídricos do Ceará, Notas Pessoais.

OBEYSEKERA, J. T. B.; YEVJEVICH, V., 1985: A Note on Simulation of Samples of Gamma-Autoregressive Variables. In: Water Resources Research 21, p. 1569-1572.

SARMENTO, F.J.; FERREIRA FILHO, W. M. 1989: Contribuição para o estudo de modelos de geração de vazãa no nordeste do Brasil. Anais do VIII Simpósio Brasileiro de Recursos Hídricos - Foz do Iguaçu - PR

SARMENTO, F.J. 1999: Ermittlung des Wasserdargebotes für die Wasserwirtschaftsplanung im Nordosten Brasiliens, Mitteilungen des WAWI, Universidade Hannover, 1997.

SARMENTO, F.J. 1999: Adequabilidade de Modelos Estocásticos de Vaz̃ão na Simulação de Reservatórios em Regiōes Semi-áridas. XIII Simpósio Brasileiro de Recursos Hídricos. Belo Horizonte - MG.

SVANIDZE, S., 1964: Fundamentals for Computing Regulation of Runoff by the Monte Carlo Method. Metsniyereba, Tbilisi.

YEVJEVICH, V., 1967: An objective approach to definitions and investigations of continental bydrologic droughts. Hydrology Paper N. 23, Colorado State University, Fort Collins.

\section{Stochastic Evaluation of Water Deficit Risk: Campina Grande Water Supply Case Study}

\footnotetext{
ABSTRACT

In this paper, the risk of exhausting the water supply for a reservoir is modeled in a 5-dimensional space. The time axis is built with a stochastic flow generation model for intermittent rivers to synthetize various possible ways of performing the stochastic process representing the inflow. The increased risk of reservoir exhaustion in a future year is fitted using a non-linear multiple regression. This procedure is applied to the case of the water supply reservoir of Campina Grande/PB - Epitácio Pessoa Reservoir (Boqueirão), for which the risk of complete exhaustion is also assessed. lated operation

Key Words: stochastic model, risk of exhaustion, simu-
} 